"The world is waking up to the biggest

shake-up in dentistry for over half a

century - and what they are waking

up to is chaos"

\title{
Extraordinary ineptitude
}

Television shots of patients queuing, a leader article in The Times and front page splashes in the tabloids - at last the world is waking up to the biggest shake-up in dentistry for over half a century. And what they are waking up to is chaos. The BDA has described the current situation as a shambles, for both patients and dentists. According to the Daily Mail, 'almost seven out of 10 dentists might quit the NHS' after 1 April. Meanwhile at the BDA, our seminars on how to convert to private practice are a roaring success.

Every day our expert advisers hear a new horror story about contract values, Units of Dental Activity (UDA) allocations and the impossibility of planning for the future. The anxiety levels are rising and practitioners are angry and frustrated. While many general dental service dentists have known their contract values and UDA requirement since December, many do not agree that they are an accurate reflection of their past activity, cannot see how they will be able to deliver them, or have been told by their Primary Care Trusts (PCTs) that there is no funding for services to which they are already committed, often entered into with the active encouragement of the PCT. The finances of the PCTs are so tightly drawn that to support those practices that are growing they are dependent on practitioners withdrawing from the NHS to 'free up' some money. Additionally if, as the Acting Chief Dental Officer has said, PCTs will not be able to know whether they have growth funding until 1 April 2006, then significant numbers of practices are being de-stabilised just at a time when they need to be managing this massive change. Patient care is bound to be affected.

of course, you could argue that we only hear the bad news on the 'phones at the BDA and as we travel across the country giving dentists our perspective on what is happening and advice on what to do. But listen to Health Minister Rosie Winterton and you will hear another story, that 'early indications' show that the vast majority of dentists are signing up to the new NHS contract. You will discover that instead of the current complicated treadmill system, dentists will soon have extra time to advise patients about better oral health. Indeed, we are looking at a bright new future for NHS dentistry, according to the Minister. So, whose spin do you believe? Readers will make their own decisions but I suspect that the picture on 1 April 2009 when the ring-fence is removed from the PCT money for dentistry will not be quite how the Government envisages.

Yet, when I met the Minister earlier this month, there was a real confidence across her team that all was well. The BDA had called for an urgent meeting to ask for the contractual requirement to deliver UDAs to be suspended until the system had been properly tested. The Minister wasn't having any of it.

My view, and it is one shared by the BDA's Representative Body, is that the new contract is not only being introduced with extraordinary ineptitude but that it is fundamentally flawed. It fails to achieve what it was meant to. It will not secure patient access, improve oral health or raise the quality of care. If you are a BDA member in England and Wales, we will be writing to you personally to explain our position and make sure you are getting all the support and advice you need. Not surprisingly, we have seen a significant increase in visits to our website (www.bda.org) which is proving a vital source of up-to-date and authoritative information for many of you.

Our priority now is to make sure dentists have all the materials and advice they need to survive this transitional period, and we will continue to keep the reality of what is happening in practices across England and Wales in the headlines.

Lester Ellman, Chair, GDPC doi: $10.1038 /$ sj.bdj.4813348 